\title{
A literature review of consumer research on edible insects: recent evidence and new vistas from 2019 studies
}

\author{
H. Dagevos \\ Wageningen Economic Research, Wageningen University \& Research, P.O. Box 29703, 2502 LS The Hague, the Netherlands; \\ hans.dagevos@wur.nl
}

Received: 9 June 2020 / Accepted: 29 October 2020

(c) 2020 Wageningen Academic Publishers

OPEN ACCESS CC) (ㄱ) (2)

REVIEW ARTICLE

\begin{abstract}
A large number of consumer studies on edible insects in Western countries have been published in 2019. A total of 33 studies are brought together in this article that provides an overview of current findings and signals further developments in today's scholarly attention in the field of human consumption of insects. To outline this body of knowledge, this literature review presents established threads of research about: (1) Westerners' unfamiliarity with; and (2) fear of eating insects; or (3) consumer reactions to processed or unprocessed insect food products. In addition, new avenues of study in entomophagy research are identified. Present-day studies open up new vistas by: (1) taking different consumer segments and food styles into account; (2) starting to examine the role of emotions and affective factors; and (3) employing a research design that includes multiple insect food products to explore consumer responses to various product options. Studies from 2019 also show that sustainability and circularity gains of insects are in their nascent stage as far as consumer studies are concerned.
\end{abstract}

Keywords: insect consumption, consumer acceptance, entomophagy, circularity, food neophobia

\section{Introduction}

'In the past few years, a veritable swarm of studies have investigated the practice and acceptance of eating insects', Ruby and Rozin (2019: 160) observe correctly. The rising publication trend of consumer studies on edible insects since 2013 (Sogari et al., 2019c: 32-33; Sogari et al., 2019d: 172) continued in 2019. It turns out that a large number of consumer-oriented studies have been published during this year. This remarkable acceleration of explorations in this field of research justifies closer scrutiny. This article reviews consumer studies on edible insects in Western countries that were all newly published in 2019. This literature review of one year of scholarly output provides an overview of current findings (Section 2), signals further developments in today's research attention (Section 3), and points to a few opportunities for future research (Section 4). It outlines the body of knowledge about the consumption of insects by bringing together a total of 33 studies from 2019 (29 articles and 4 book chapters). This collection was brought together by executing literature search from mid-2019 to mid-2020. In the course of this period multiple rounds of literature search were conducted in the electronic databases Scopus and Google Scholar, using several search queries with the following key words: 'edible insect', 'consumer edible insect', 'consumer acceptance insect', 'insect consumption', and the time set on '2019' or 'since 2019'. To exclude irrelevant research areas and because of the focus on consumer studies, key words such as 'consumption' and 'entomophagy' were included. References in alreadypublished papers also provide some additional studies as well as personal knowledge of the author about books published in 2019 containing relevant chapters for the objective of this literature review on entomophagy, i.e. the human consumption of insects.

After their review of studies devoted to reactions and the readiness of European consumers to accept insects as food, Mancini et al. (2019a: 676) draw the following conclusion: 'Despite the advances in research, the potential of insects as food is still poorly understood. Based on an extensive review of the existing literature on consumer acceptance of 
insect-eating, Kauppi et al. (2019: 57) conclude that this field of research is still 'rather fragmented'. Even if we sympathise with such conclusions, we should not lose sight of the fact that we already have gained considerable understanding. A number of outcomes have been corroborated across various consumer studies on edible insects. The following section is devoted to the results obtained by current research. It shows what consistent evidence has been found as yet. Section 3 demonstrates in what exploratory directions the thriving research area on 'creepy, crawly and flying food' is evolving nowadays. Sections 2 and 3 are connected in the sense that the new vistas identified and discussed in the successive three subsections of Section 3 are in line with findings presented in each of the three subsections of Section 2. In the closing section, Section 4 , special attention is paid to environmental benefits and circular aspects of insects as food, and a few topics are raised for future research.

\section{Benefits and barriers of eating insects}

Despite barriers and reservations, researchers search for potential drivers of consumer appeal and acceptability, and investigate which Western consumers are possibly more receptive to incorporate edible insect food products into their habitual food consumption pattern. Doing so has become all the more urgent in recent years because of the worrisome global and interrelated developments of climate change, world population growth and accompanying growing animal protein demand, resulting in sky-rocketing meat production and consumption. From this viewpoint the production and consumption of insects offer a substantial contribution to food security, environmental sustainability, as well as healthy diets (for a recent and overall review of the area of insects, see De Carvalho et al., 2019). Small wonder that the benefits of food insects and the pressing need to introduce these in the repertoire of the Western diet are emphasised. References to the advantages of insects in terms of environmental sustainability (feed conversion ratios, low carbon, land, water, footprint) human health and food security (low in carbohydrates, rich in proteins and fats, important vitamins and minerals) - particularly in comparison to conventional meat products as source of protein - are becoming as commonplace as referring to Western consumers standing aloof from insects as food. As a result, at the beginning of current consumer research on edible insects one can usually read about both the difference - potentially - the consumption of insects and insectbased food products could make to assist environmental sustainability, human health and food security on the one hand (often accompanied by a reference to the groundbreaking publication by Van Huis et al., 2013), and its problematic reception - in practice - in contemporary food consumer preferences and practices in European countries or other parts of the Western world on the other (e.g. Castro and Chambers, 2019; Hartmann and Siegrist, 2017a; Hartmann and Bearth, 2019; Kauppi et al., 2019; Lombardi et al., 2019; Orsi et al., 2019; Poortvliet et al., 2019; Woolf et al., 2019).

When these two general statements are taken together, it is striking to note that still in studies from 2019 the advantages of eating insects on planetary and personal levels turn out to be not self-evidently important enough to overcome existing consumer barriers to eating insects. What is more, environmental reasons as a driver of Western consumer acceptability of insects as a sustainable source of food for humans, are not a consistent and critical factor in current research. Apart from the fact that these have not always been taken into account, when included in research, sustainability consciousness and concerns do not automatically lead to consumer support for eating foods of insect origin (e.g. Lammers et al., 2019: 85). At the same time, the urgency grows to decrease the ecological footprint of the meaty and dairy-rich diets in Europe and other parts of the Western world. Finding alternative protein sources for the consumption of conventional meat and dairy products with lower environmental impact is, consequently, gaining momentum. Insects provide opportunities in this respect.

The current popularity of circularity adds to this. Since insects are highly efficient in converting plant-based by-products and food leftover streams into high-quality protein, insect rearing is inherently circular. This is recognised, for instance, by Orsi et al. (2019: 1), who refer to 'the concept of circular economy' with respect to raising insects, by Kauppi et al. (2019: 42, 57), who hint at 'circular economy principles', and by Aiking and De Boer (2019: 6), who indicate: 'The potential of insects is not only relevant for food and feed but also for (...) a transition towards a circular economy.' While the sustainable merits of insects in novel production cycles within the 'new' circular economy have been taken recently as a starting point of investigation and improvement, circularity as an asset in stimulating consumer demand is mainly non-existent as yet. The framing of the production and consumption of insects in circular terms is undoubtedly an interesting perspective for future research. Within the context of the much-denoted problems of sustainable and healthy diets for a growing world population, such a circular approach has been taken up recently when it comes to research focusing on insect production (see Madau et al., 2020, for a timely work that calls for insect farming from a circular economy perspective). Time will tell whether and how circularity challenges become a point of reference for consumer studies on edible insects in the coming years.

\section{Other recent review articles}

After pointing to this idea for future consumer research, let us return to consumer studies conducted in recent years and, more specifically, to research published in 2019 
devoted to consumer acceptance and adoption of insecteating and insect-containing foods. The following section summarises some of the main results of previous studies. In order to take former studies together, both Mancini et al. (2019a) and Sogari et al. (2019c) deliver valuable and up-to-date reviews. Because both review articles put much emphasis on methodological issues while the present work is primarily interested in research findings, an additional review is included. Although not published in 2019, the review paper by Hartmann and Siegrist (2017a) is a recently-published one and recapitulates nicely various conclusions which can be drawn from previous consumer studies on insect-based food products (for a succinct version of their findings concerning consumer acceptance of insects as food in Western nations, see Hartmann and Siegrist, 2017b: 21-22). The latter also holds for the literature study by Kauppi et al. (2019) that assesses edible insects consumer research conducted between 2005 and 2018. Both Kauppi and colleagues' as well as Mancini and colleagues' and Sogari and colleagues' review articles published in 2019 present the state of play till 2019, and the current article adds to these by concentrating on consumer studies in entomophagy published in 2019. The review by Mancini et al. (2019a) includes three 2019 papers (by Jensen and Lieberoth, by Lombardi $e t$ al., and by Van Thielen $e t$ al. to be more precise) that are also included in our collection of articles. The scoping review by Sogari et al. (2019c) includes the Mancini et al.-review (2019a) and three studies by Sogari et al. (2019a,b,d) that also belong to the collected consumer studies in the present literature review.

\section{Evidence: what do we know?}

During the second decade of this century, consumer research on the practice of eating insects has resulted in several findings that have been frequently pointed to. Lammers et al. (2019: 79) even talk about 'classical' variables in the field of entomophagy. Such classics examined in previous research are familiarity with eating insects, food neophobia, attachment to eating meat, or consumer reactions to processed or unprocessed insect food products (see e.g. Orsi et al., 2019: 2-4; Ruby and Rozin, 2019: 156; or Schäufele et al., 2019: 2191-2193 for brief overviews of key factors influencing consumer acceptance of insects as food).

\section{Appetite for insects: unfamiliarity, meat attachment, and gender}

One of the most prominent truisms in studies on entomophagy is the recognition that eating insects does not belong to the traditional Western diet, making it anything but a sinecure for entomophagy to become part of the habitual food pattern of Western consumers. This line of reasoning is generally subscribed to, as a selection of quotes may illustrate:
Overall, it is evident that it will be a great challenge to convince western consumers of the advantage of entomophagy. (Hartmann and Siegrist, 2017a: 49)

Generally, western consumers don't regard foods of insect origin as a delicious and nutritious option. (Elorinne et al., 2019: 3)

Of course, for many westerners, insect-based foods are still unusual and unappealing. (House, 2019a: 454)

In Western cultures in particular, insects are not considered appropriate for consumption. (Iannuzzi et al., 2019: 454)

The vast majority of people in the West are still not ready to add insects to their daily diets. (Kauppi et al., 2019: 40)

Acceptance rates of insects as foodstuff by consumers in Western countries are generally low. (Kornher et al., 2019: 2)

Particularly, in urban and Western societies, insects are rarely eaten or their consumption is perceived to be culturally inappropriate. (Mancini et al., 2019b: 1)

Insects are currently far from being a regular part of Western diets. (Onwezen et al., 2019: 51)

Entomophagy is far from common practice in many Western societies. (Poortvliet et al., 2019: 1)

In Europe (...) consumer acceptance to try and eat and in particular to integrate edible insects in their habitual eating routines, is far from having been overcome. (Rumpold and Langen, 2019: 45)

In Europe and other Western countries, this practice [of consuming insects as food] has never been widespread and remains rare. (Sogari et al., 2019d: 170)

Such remarks make it obviously clear that we have to deal with a food cultural unfamiliarity of Western consumers with eating insects. This proves to be a major obstacle to both consumers' willingness to eat foods of insect origin and their acceptance of insects as a sustainable alternative source of animal protein. Rather than insects appealing to consumers, research shows that consumers often react with a natural aversion to insects as food. Low levels of willingness and intention to try insects, and reluctance to eat unfamiliar foods appear to be two sides of the same coin. The latter refers to food neophobia. A high level of food neophobia implies a low inclination to try new foods. This holds the other way around, too: low levels 
of food neophobia signify variety or sensation seeking by 'neophilic' food consumers. These consumers represent a minority as yet. It is more commonly found that European consumers' primary reactions to insects as food are not very enthusiastic and receptive. Corresponding to this kind of reception, consumer research on eating insects has highlighted from the beginning a few decades ago until now that the emotion of disgust is an influential factor in the way many Western consumers qualify insects as food. This disgust-based rejection is vividly expressed by Chan as he refers, in the opening sentence of his paper, to 'a view of insects as dirty, dangerous, and disgusting' (Chan, 2019: 375; see also Castro and Chambers, 2019: 8-9; or Orsi et al., 2019: 2). In their turn, Poortvliet et al. (2019: 1005) add another Triple D of 'dirt, diseases, and death', to formulate negative associations with insects which help to find determinants that hamper the consumption of insects as food.

These negative associations surrounding appetite for insects and entomophagy acceptance contrast sharply with the much-supported consumer beliefs in the Western world about meat consumption that are known as the 4Ns: eating meat is natural, normal, necessary, and nice (Piazza et al., 2015). Consequently, this 'sacrosanct' position of meat in contemporary Western diets may represent another main hurdle to overcome to increase consumer approval of insect foods - irrespective of being perceived as a novel protein source or, more specifically, as a meat substitute. Meat attachment may intervene, then, with consumer willingness to try and buy insect food products as an alternative nutrition source of protein (previous studies in Belgium and the Netherlands subscribe to this view - see Lammers et al., 2019: 79, 81 for relevant references). Although Sogari et al. (2019b: 10) did not find a specific link between current meat consumption frequency and openness to insect-eating among their 555 Australian participants who belong to the Millenials and Generation Z, i.e. 18-40 years of age, Kornher et al. (2019) yield a consistent finding to the line of reasoning that meat attachment of an established diet influences entomophagy acceptance and adoption: their study shows that respondents who report infrequent and low consumption of meat products declare to be more likely to adopt insect consumption in the foreseeable future. With respect to positive meat attitudes and their possible impact on accepting insects as food, Van Thielen et al. (2019: 40) indicated that the group of potential insect consumers includes fewer people who eat meat every day, whereas the group of respondents who are not interested in trying insects contains more 'real meat eaters'. Because generally men are more attached to eating meat, one would expect to find that women are more inclined to take eating insects into consideration. However, current consumer research on gender issues related to insect eating is not only limited but also mixed in its reported results. Earlier studies before 2019 suggest that women are more unwilling than men to accept insects as food, while in other studies such gender differences were less significant. To refer more explicitly to one of the included papers, Lammers et al. (2019: 84) in their turn demonstrated that gender only influences the willingness to eat whole insect food products. Male respondents turn out to be more willing to consume unprocessed insects (buffalo worms in this case) than female respondents. However, with respect to the readiness of men and women to eat a processed burger containing invisible insects, no significant differences were found in their willingness to try this insect-based food product, though. A similar result is obtained in the study by Orsi et al. (2019: 13).

\section{Entomophagy acceptance: experience and information}

Switching from negative attitudes to positive ones, it is noteworthy that consumers who have already positive taste experiences with insect eating appear generally more willing to eat insects again and to temper negative reactions. In accordance with behavioural theory, the importance of past behaviour to the choices to make is repeatedly addressed in modern consumer research on edible insects (e.g. Kornher et al., 2019; Lammers et al., 2019; Orsi et al., 2019; Palmieri et al., 2019; Ruby and Rozin, 2019; Van Thielen et al., 2019; Woolf et al., 2019). Sogari et al. (2019a) corroborate that a higher past exposure to edible insects plays a significant role in reducing food neophobia scores with respect to trying edible insects again. In brief, previous and personal experiences with consuming insects are likely to generate positive taste expectations for future tastings. Prior exposure, then, may be seen as the flipside of the justmentioned food-cultural variable of unfamiliarity. As long as Western consumers have little to no experience with eating insects, it remains exotic and will not establish popularity.

A stepping stone towards creating more consumer attention and connection, is providing information. Modern research investigates the role of information and its effect on consumer attitudes and associations towards edible insect food products (e.g. Legendre et al., 2019; Rumpold and Langen, 2019). Generally, information provided about the nutritional or environmental benefits of insects as foodstuff is helpful to raise acceptance rates. In the same vein, a higher level of information, that is, being more aware of possible benefits of eating insects, relates positively to consumer willingness to eat insect-based foods (Lombardi et al., 2019; Mancini et al., 2019b; Palmieri et al., 2019; Ruby and Rozin, 2019; Woolf et al., 2019). Mancini et al. (2019b), for example, found that after attending a three-hour informative seminar about ecological and health aspects of entomophagy, student participants' negative perceptions had changed. Particularly disgust decreased significantly, indicating a more positive attitude to the acceptance of insects and insect-containing foods. 
With respect to information, two additional comments could be made. First, we remark and remember that a flood of behavioural change research has shown that information alone is not enough to result in (lasting) behavioural change. However, information and awareness are basic preconditions to possible change in behavioural choices and habits. Second, consumer responsiveness to information highly depends on one's interests: those people who are less interested in nutritional or environmental benefits of the foods they eat are less likely sensitive to information about healthy or climate-friendly aspects of insects as food. An illustration of the unexpected impact of information is provided by Van Thielen et al. (2019: 40), who found that the provisioning of information to consumers without experience and interest regarding consuming insects about advantages of edible insect food products, resulted in a majority (57.9\%) that sticks to a negative response to the question whether they would consider adding insectcontaining food products to their diet. Despite their initial unwillingness to taste edible insects, the rest (42.1\%) appear to be responsive to the information provided and mention they expect to be more open-minded from now on to the consumption of insect-based foods.

\section{Entomophagy by stealth: hidden is supposed to be best}

Poortvliet et al. (2019: 1005-1006) mention that in the beginning of the introduction of insects as edible foodstuffs, the initial idea was to supply whole insects to the market, often in fried form and meant as snack. Nowadays, this approach does not prevail anymore. Although eating the whole insect could be attractive to culinary adventurers (Aiking and De Boer, 2019: 5; Hartmann and Siegrist, 2017a: 49) and sensation seekers (Lammers et al., 2019: 85 ), the dominant market strategy currently is to follow a development similar to plant-based meat substitutes. That is, consumer adoption is searched for by preparing palatable and familiar foods based on processed insects. Like plant-based meat analogues which aim to look and taste like conventional meat products as much as possible, insect-containing foods use a familiar carrier product such as burgers, bread, biscuits, crackers, crisps, candy bars, shakes, soups, sauces, or pasta. The appearance of such sophisticated processed foods is similar to products which belong to the daily diet of many Western consumers. The rationale behind this strategy is that eating bugs is more acceptable to Western consumers when they are first made more familiar with eating foods of insect origin through the consumption of highly processed foods containing insects in crushed, bruised or powdered forms. In this way, insects are eaten in visual absence: insects are going under the radar. In imitation of what I have named earlier 'seaweed by stealth' (Van den Burg et al., 2019: 4), I would like to term this 'entomophagy by stealth'.
It is widely believed that entomophagy by stealth generates better prospects for consumer acceptance as well as offering more viable opportunities to positive taste experiences. This idea of 'hidden is best' is also supported by empirical evidence (e.g. Lammers et al., 2019) revealing that consumers are more open to adopt eating invisible insects in familiar-looking and tasting foods than accepting the whole insect as food or the presence of unprocessed insects in a food product. Disguising processed insects in familiar food products, then, is taken as a promising pathway to reduce disgust-based aversion towards eating insects and to raise the likelihood of consumer acceptance and adoption (Aiking and De Boer 2019; Castro and Chambers, 2019; De Carvalho et al., 2019; Jensen and Lieberoth, 2019; Mancini et al., 2019a; Ruby and Rozin, 2019; Sogari et al., 2019a,b). In the words of House (2019a: 454): 'Processing and use of familiar products are argued to mitigate the 'yuck factor' and encourage consumption.' Likewise, Schäufele et al. (2019: 2200) note 'the degree of processing is a key factor in enhancing consumer acceptance.' Or, to put it in the words of Kusch and Fiebelkorn (2019: 2):

The most promising strategy for increasing the currently low acceptance rate of insects as food is preparing them in a form that resembles known products, like chips or burger patties.

The possible merits of entomophagy by stealth also emerge from the results obtained by an insect-oriented survey study among US consumers by Woolf et al. (2019). Their research shows that a major barrier to more positive perceptions of entomophagy are food products containing visible insects while foods containing invisible insect ingredients are helpful to overcome consumer reluctance and disgust. This finding confirms the often-found relationship between higher consumer acceptance and lower visibility of insects, and vice versa.

\section{New vistas: where does research go to?}

The preceding section covers main findings of consumeroriented research on entomophagy that have been obtained in recent years and given attention as well as corroboration in papers from 2019. To outline the state of the art of research into the consumption of edible insect food products, this literature review does not concentrate only on results obtained and topics addressed but also on newly-developed threads of research. In addition to the evidence provided in the previous section, new avenues of consumer study in entomophagy research that have been published in 2019 are identified in the subsequent three subsections. 


\section{Different segments of food consumers respond differently to insect eating}

In line with the presentation of previous findings in the first subsection of Section 2 on the importance of past behaviour and habitual food consumption patterns with respect to consumer receptiveness and willingness to try eating insects, present-day studies open up a new vista by taking different consumer segments and food styles into account rather than taking consumers as a uniform group, to explore how consumers differ in their attitudes and acceptance.

Making differentiations between consumers is not uncommon in entomophagy studies. Early adopters of insect food products, for instance, are frequently depicted as variety seekers, adventurers, or believed to be found especially among young adult males (Hartmann and Bearth, 2019; Kauppi et al., 2019; Kornher et al., 2019; Palmieri et al., 2019; Orsi et al., 2019; Sogari et al., 2019a; Van Thielen et al., 2019). In their consumer segmentation study on eating insects, Brunner and Nuttavuthisit (2019) showed that $9.3 \%$ of the 542 Swiss respondents of the distributed questionnaire belong to the early adopters. This segment is characterised by low levels of food neophobia, experience with insect eating or ready for it, and high education levels. Following the well-known categorisation of Rogers' theory of diffusion, the next segment in the study by Brunner and Nuttavuthisit is the early majority (32.5\%), showing hesitant willingness to insect eating. In the following segments of late majority (27\%) and laggards (31.2\%) reluctance and food neophobia rise and educational levels drop. Brunner and Nuttavuthisit (2019:484) do not refer to gender differences but briefly raise the point that particularly laggards are highly attached to the meaty dishes they are accustomed to. This accords with the reasoning that (female) consumers who cling more to their vested food practices are less likely to belong to the prime target groups of edible insect food products.

Van Thielen et al. (2019) make a corresponding distinction between three groups of their Belgian respondents that differ in experience with entomophagy: a small group of respondents who had already eaten insect-based food products (of which around half of them declared it was a one-time experience, whereas the other half had eaten insects several times), a group without any experience with consuming processed insects but curious to taste such foods, and, finally, a large consumer group consisting of respondents who had neither experience nor appetite to eat foods that contain insects.

A more innovative way to differentiate consumer groups with respect to their attitudes towards entomophagy is provided by Elorinne et al. (2019). Rather than base consumer segments on socio-demographic variables such as age or education level (variables, by the way, which give as yet no convincing results to make clear-cut distinctions between consumer segments, see also Woolf et al., 2019), Elorinne and colleagues chose to explore consumer attitudes and intentions towards insect consumption along the line of different dietary groups. Put differently, different food styles are taken as a way to divide consumers into respectively omnivores, non-vegan vegetarians, and vegans. This is a reasonable thing to do considering the relevancy of routinised eating patterns and practices for consumers' inclination to try novel foods such as foods of insect origin. The approach of Elorinne and colleagues demonstrates that non-vegan vegetarians' attitudes towards eating insects were the most positive whereas vegans held the most negative attitudes towards insect consumption and expressed low intention and willingness to eat insects of any kind because they regarded this as immoral and irresponsible:

Vegans agreed the most with the following statements: 'Insects should not be used in food production,' 'Foods made of insects are a bad thing,' 'I want to be an ethically responsible consumer and I don't want to utilise insects in my own diet,' and 'The use of insects in food production is morally wrong.' (Elorinne et al., 2019: 8)

Taking different dietarian identities, as Elorinne and colleagues term it, as a starting point reveals that vegans deviate substantially from the adherents of the two other dietary groups of omnivores and non-vegan vegetarians when it comes to their views on the consumption of foods of insect origin. Vegans mostly belong to the group of 'unlikely consumers' given their attitudes and intentions, as opposed to a majority of the omnivores and non-vegan vegetarians who more likely belong to consumer groups of potential insect food eaters in the near future.

The vegan food style is not only interesting because many vegans seem to be quite determined in their rejection to incorporate insect foods in their diet. The position of vegans, and to a lesser extent vegetarians, on insect foods is also fascinating because intention and willingness to consume edible insects has various motivations ranging from affordability, availability, convenience, and safety to nutritional value, ecological reasons and animalfriendliness. Particularly the latter is a pivotal consumer concern of vegans. At the moment, it is unclear how huge a hurdle this issue is going to be to vegans with respect to their opinions about the raising of insects and the accompanying consumption of insect-based food products. Will all vegans be strict in keeping their diet animal-free or will they be open to insect-derived food products as an alternative source of protein? Will vegans abstain from eating insects because the avoidance of consuming animals overrules concerns about their ecological footprint or about food security? Remarkable in this respect is the observation 
by Rumpold and Langen $(2019: 45,53)$ that roughly half of their vegan - as well as vegetarian - participants $(n=19)$ were willing to taste insects, and saw no reasons to not eat insects because of decisive environmental reasons. Proper sustainable proteins appear more important to these vegans' - and vegetarians' - attitudes towards insect consumption than proper animals, so to say. However, Orsi et al. (2019: 13), in turn, report that the small number of vegetarian and vegan respondents in their online survey found eating insects repulsive. Schäufele et al. (2019: $2197,2201)$ note that more than half of the vegetarian and vegan participants in their initial sample avoid eating insects because of their diet, whereas the other half of them give serious consideration to insect consumption. Without delving deeper into this, it suffices here to mention that both Ruby and Rozin (2019: 162) and House (2019b: 204-206) draw attention to the topic of insect acceptance by vegetarians along criteria of the ethical treatment of animals, and suggest that the issue of animal welfare with respect to insect rearing and consumption is anything but determined.

\section{Emotional aversion and affection}

Supplementary to the evidence collected in the second subsection of Section 2 on the emotion of disgust, current scholarly attention is drawn to the possible influence of consumer feelings and state of mind regarding adoption of insects as food. Disgust has been both a primary and a major aversive reaction in Western cultures towards insect consumption since pioneering research on entomophagy in the '80s and '90s until contemporary studies. This finding may be regarded as a stepping stone for highlighting the role of emotions in entomophagy. In addition, this viewpoint is justified by the fact that cognitive strategies (information or education on, for instance, nutritional or environmental benefits of the use of insects as human food) alone are usually not enough to generate profound behavioural consequences. The rationality of consumer choices is bounded.

From this perspective, Chan (2019) experiments with mindfulness as a state of mind that could affect willingness to try insects as food. The subsequent three experiments conducted show that the feeling of disgust associated with insect foods remains. Being mindful turns out to have no lowering effect on respondents' unwillingness to try insect-containing foods (in this case: silkworm-enriched drinks), but seems rather to 'exacerbate disgust' (Chan, 2019: 381). The emotional reactivity effect of mindfulness does not hold for feelings of disgust as primary response to choose insects as food. This brings Chan (2019: 381) to the conclusion 'that mindfulness may not be particularly useful in entomophagy'

A study by Onwezen et al. (2019) also takes as a starting point that food consumer appeal and appetite (to change) is not only a matter of cognitive deliberations or practical convenience. In this respect, Orsi et al. (2019: 14) simply and justly state that 'entomophagy is still a delicate and emotional topic for many consumers'. Moreover, in the case of unfamiliar foods we have little information about and experience with, the role of affective associations and intuitions is often even more important. Furthermore, and mentioned above, research on Western consumer acceptance of insects as food source has made it abundantly clear that the role of emotional reactions of disgust are a major barrier to entomophagy acceptance (e.g. Hartmann and Bearth, 2019). High time, according to Onwezen et al. (2019) to put more emphasis in research on the role of affective factors in consumer acceptance of insect eating. Taking various positive (happy, proud, satisfied) and negative (guilty, angry, sad) emotions into account, and conducting three different studies, this research by Onwezen $\mathrm{et} \mathrm{al}$. provides confirmative empirical evidence for the hypothesis that consumer feelings and affective associations are indeed important - particularly regarding the acceptance of novel foods, such as insects, compared to more traditional protein products, such as pulses, as well as the acceptance of foods that are more obvious of insect origin (i.e. fresh, dried or fried insects). This is on par with just-mentioned results obtained in the field of entomophagy by stealth, but Onwezen et al. supplement to this by indicating that affective variables greatly affect the acceptance of insect-based products. In exploring the effect of affective processes on consumer intentions, Onwezen $e t$ al. included a broad range of insect foods (fresh, dried and fried insects, a burger made from whole insects, a burger made from chicken which were fed with insects) as well as different protein food products (pulses, seaweed, fish, meat). Taking several product alternatives together in one study alludes to a third new vista that is identifiable in entomophagy studies from 2019.

\section{Including multiple edible insect options in research design}

As indicated above and in addition to reflections and results concerning entomophagy by stealth in Section 2, a third new vista in today's consumer research on edible insects is opened up by taking multiple insect food products into account in one and the same study in order to explore consumer responses to different product options. What is more, in addition to different foods containing insects also comparisons between insect foods and foodstuffs based on other protein sources have been made in entomophagy research (e.g. Kusch and Fiebelkorn, 2019; Poortvliet et al., 2019) - as well as the other way around: insect options have made their entrance in consumer studies devoted to meat alternatives or sustainable product alternatives more generally (e.g. Circus and Robinson, 2019; Grasso et al., 2019; Powell et al., 2019). The issue of invisible/visible insect ingredients in food products has raised scholarly momentum for this type of research design, as may be 
illustrated by referring to Jensen and Lieberoth, 2019; Kornher et al., 2019; Lammers et al., 2019; Lombardi et al., 2019; Orsi et al., 2019; Poortvliet et al., 2019; Ruby and Rozin, 2019; Woolf et al., 2019 as cases in point. As a result, it has become customary in current research to present different product choices to respondents, e.g. a mealworm-based nutrition bar and a mealworm burger (Berger et al., 2019), pizza made with flour, pizza made with cricket flour, pizza made with cricket flour and spirulina algae (Iannuzzi et al., 2019); a 'hybrid' insect burger made out of pulverised insects mixed with beef and a conventional (bovine meat) burger (Kornher et al., 2019), a meat burger containing solely beef, a hamburger patty consisting of vegetarian ingredients, or an insectbased burger consisting of a mix of ground insects and vegetarian ingredients (Kusch and Fiebelkorn, 2019), spring rolls with invisible/visible insects or buttermilk soup with invisible/visible insects (Jensen and Lieberoth, 2019), a 'hybrid' insect burger made out of buffalo worms which are stirred into a mass of vegetarian ingredients and unprocessed buffalo worms (Lammers et al., 2019), tacos with unrecognisable/recognisable grasshoppers, transparent lollipops containing a mealworm or a grasshopper (Ruby and Rozin, 2019), or, burger patties made out of ground beef or ground buffalo worms, a mealworm and locust-based shish kebab or skewers with cubes of veal and insect meat (Poortvliet et al., 2019).

An often-used way of presenting the options to consumers are by showing food pictures to the participants (e.g. Berger et al., 2019; Jensen and Lieberoth, 2019; Kornher et al., 2019; Kusch and Fiebelkorn, 2019; La Barbera et al., 2019; Orsi et al., 2019; Poortvliet et al., 2019; Ruby and Rozin, 2019; Schäufele et al., 2019). Poortvliet et al. (2019: 1008-1009) found that their Dutch participants were particularly responsive to exotic product options such as an uncommon product as insect-based shish kebab rather than to a burger. Therefore, they suggest that a successful entomophagic adoption in Western food cultures could be generated by introducing insects via special food products which, for instance, originate in Mediterranean or other 'ethnic' cuisines. This opinion contrasts with a widelyshared observation by Mancini et al. (2019a: 675-676) about improving consumer acceptance of novel insect food products particularly through their integration into familiar dishes and local diets, as well as their availability and accessibility in mainstream supermarkets and restaurants. With respect to the latter, Sogari et al. (2019c: 41) rightly claim: 'Increased visibility of insect products in restaurants, supermarkets and street food trucks is another crucial aspect.' Nevertheless, the suggestion by Poortvliet et al. is valuable considering that it is going to be difficult to convince modern consumers in Western societies that insects are 'the new meat'. Rather than positioning insects and insect-containing food products as meat substitutes, their suggestion inspires to think further about giving insects and insect-based foods new product designs or application forms that deviate from traditional meat and established food practices.

\section{Concluding thoughts and looking ahead}

The just-cited remark by Sogari et al. (2019c) about the lack of visibility of insect products in today's food outlets, brings us to a first avenue for future research. Given the modest availability of insect products in the current market, it is understandable that most recent studies put much emphasis on the individual psychology of food choice (e.g. food neophobia, knowledge of entomophagy, vested food habits) with respect to consumer readiness to embrace entomophagy in their diet. When insect or insect-enriched products become more available and insectlabelled products more visible in places where consumers usually do their groceries, however, it will become more relevant to acknowledge that individual consumer food choices are powerfully affected, shaped and cultivated by the socio-cultural and physical environment. Given that the market penetration of insect food products is still in its infancy, it is perhaps a bit too soon to put much emphasis on the investigation of social factors influencing the incorporation of edible insects into people's diets. However, if entomophagy is going to proliferate in food markets and food consumer culture of the Global North in the near future, it seems wise for future research to follow the steps of early studies focusing on social practices and contextual factors (House, 2019a), social acceptance and eating norms (Jensen and Lieberoth, 2019; Schäufele et al., 2019), or the social network influence of peers and experts (Berger et al., 2019) in its endeavours to gain further understanding of entomophagic acceptance and adoption processes.

How important the low availability of insect food products and dishes consisting of insects may be, it is just one of the determinants in consumer willingness to entomophagy in Western countries. The promotion of consuming insects also highly depends on taste (sensory appeal), price (affordability), the ability to prepare insect foods and dishes (food literacy), appropriateness, attunement to cherished eating norms and food culture, nutritional value, food safety, as well as ethical and health reasons, and, last but not least, sustainability concerns. It is to be expected that particularly nutritional features of insects (Van Huis, 2020) and health motivations of consumers as drivers for the adoption of eating insects (e.g. Poortvliet et al., 2019) will gain more scholarly interest in the coming years. However, because of our special interest here in sustainable and circular merits of insect eating, we confine our concluding thoughts to a few reflections on this issue.

From the perspective of raising insects many scholars subscribe to the general view that the production of insects has clear environmental advantages because of 
high feed-conversion efficiency, low water and space use as well as upcycling of food waste streams into highquality proteins. Particularly in comparison to conventional livestock farming and its accompanying GHG emissions, the production of insects generates an overall smaller ecological footprint (for further details, see such recent studies as the ones by Alexander et al., 2017; Parodi et al., 2018; Van der Weele et al., 2019). Discussion is open about the amount of pressure that insects as source of animal protein exert on the environment, 'depending on the species, food fed to the insects, and economies of scale' (Ruby and Rozin, 2019: 155), as well as taking into account that 'insects are often raised in heated rooms and then freeze-dried, oven-dried, blanched, ground up, and sometimes dehydrated, all of which consumes significant amounts of energy' (Kauppi et al., 2019: 55). At the same time, broad scientific consensus exists about the environmental friendliness of insects and the promising contribution of 'minilivestock farming' (to borrow a term (re)used by Stull and Patz, 2020) to circular agriculture because of the ability to convert low-grade resources (organic by-products and waste) into high-quality proteins (whole insects) and protein ingredients (processed insects) for both food and feed.

A new avenue of study lies open for future entomophagy research that combines production practices of insect rearing with consumer perceptions on whether consumers consider insect farming as less harmful to the environment (in comparison to conventionally produced animal protein) and to what extent this reduces their aversion and raises their acceptance. Or perhaps the route of insects as livestock feed might be the shortest way to the food market - e.g. eggs of laying hens that have been fed insects, or a burger of ground meat derived from insect-fed chickens. The 2019 studies by Kauppi et al., La Barbera et al. and Onwezen et al. offer inspiration for this approach of 'indirect entomophagy', as La Barbera et al. (2019) call it, that concentrates on eating products of animals fed with insects instead of focusing on eating raw or processed insects.

\section{Sustainable benefits}

From a consumer perspective, evidence across 2019 consumer studies suggests these environmental sustainability benefits hardly make contemporary Western consumers tick at present. On the one hand, and already indicated in the introductory section, many entomophagy studies pay relatively little attention to positive attributes of insect eating on the environment. The comment by Berger et al. (2019: 1) that 'eating of insects in Western markets has been primarily discussed from an environmental perspective' is arguably an exaggeration. That is, sustainability issues are not prime. This holds even more for circularity. So far, this point of view is only in its embryonic stage. Hence, when Hartmann and Bearth (2019: 52) point out that 'environmentally inclined consumers might perceive the possibility of converting food waste into high-quality protein as beneficial', they actually make a pioneering statement and refer simultaneously to a topic of future consumer studies on edible insects devoted to answer the questions to what extent and to whom it is appealing that insect production and consumption meet circular principles.

On the other hand, findings of 2019 entomophagy research deliver mixed results on sustainable benefits of raising and eating insects as a core motivator of consumer appeal to eating insects. This result is consistent with pre-2019 consumer studies on edible insects in which environmental advantages are found both significant and of little importance to consumers (Mancini et al., 2019a: 672-675). The latter is frequently due to consumer unawareness or lack of confidence in environmental sustainability gains of insects as novel edible protein source - followed just as frequently by the scholarly suggestion that messages stressing sustainability advantages of edible insects could influence consumer acceptance and adoption positively (Mancini et al., 2019b). Recent increased media interest in paying attention to consuming insects as food could also be helpful in improving the image and level of information of insects as a new and sustainable source of food. With respect to findings from 2019 research, Lammers et al., or Orsi et al. are examples of studies drawing more pessimistic conclusions about sustainable benefits of entomophagy and their effect on increasing Western consumer likelihood to adopt insects into their existing diets. As opposed to this, the 2019 studies by Kornher et al., Palmieri et al., Schäufele et al., or Sogari et al. (2019d) are examples of current research that provide evidence for a more optimistic interpretation in which environmental benefits of entomophagy contribute to convince modern Western consumers that insects as food are an alternative source of animal protein for humans that, subsequently, positively affects consumer intention to adopt insect consumption.

At least two arguments could be given to expect that it will be hard for environmental advantages to become a decisive argument for consumers in favour of eating insects. First, Brunner and Nuttavuthisit (2019) provide evidence for the idea that a minority of consumers assesses sustainability arguments as relevant to the attractiveness of insects as food. This is in accordance with a systematic review by Sanchez-Sabate and Sabaté (2019) pointing out that environmental reasons are not a major motive in dietary change for the general Western population so far - despite climate change, global food security problems and rising cost of animal protein. In addition, and outlined above, rational reasons often do not determine food preferences and consumer choices - particularly when feelings of fear, disgust and unfamiliarity are involved. Second, what has been coined here as entomophagy by stealth with its focus on unrecognisable insects in processed food products 
that are familiar, tasty, healthy and safe to eat, undermines sustainable benefits of insect food products because of the bigger ecological footprint of processed insect foods. Eating the whole insect is a better option from a sustainable viewpoint, but also across many 2019 studies it has been found that putting unprocessed insects into your mouth is to most of us in the West still considered a food taboo. Thus, the (marketing) strategy of 'hidden is best', which is currently considered to be a promising way to move forward in order to overcome sceptic attitudes towards insect eating, is more difficult to relate to environmental sustainability gains.

\section{A strenuous challenge}

All in all, 2019 entomophagy studies reveal that many Westerners remain hesitant to include insect eating into their daily diet, and consequently, the evidence suggests that the eating of insects is anything but widespread and common but rather surrounded by unfamiliarity and reluctance. Briefly put, insects are hard to swallow. Undoubtedly, then, it is going to be a strenuous challenge to make insect eating a normal, nice as well as natural and necessary thing to do. Therefore, we should not overestimate consumer appetite for bugs and should be careful too with prospects about insects as 'food of the future' in Western countries. The current state of affairs remains that it is not a daring prognosis to say that it will take a while before the time has come in which we have learned 'to love their [insects'] crunchy umami taste and to value this nutritious, low-impact source of protein' (Steel, 2020: 277). Nevertheless, it is also wise to bear in mind that 'the adoption of new foods comes with challenges, but altering cultural tastes is not insurmountable' (Stull and Patz, 2020: 639).

\section{Conflict of interest}

The author declares no conflict of interest.

\section{References}

Aiking, H. and De Boer, J., 2019. Protein and sustainability - the potential of insects. Journal of Insects as Food and Feed 5: 3-7. https://doi.org/10.3920/JIFF2018.0011

Alexander, P., Brown, C., Arneth, A., Dias, C., Finnigan, J., Moran, D. and Rounsevell, M.D.A., 2017. Could consumption of insects, cultured meat or imitation meat reduce global agricultural land use? Global Food Security 15: 22-32.

Berger, S., Christandl, F., Bitterlin, B. and Wyss, A.M., 2019. The social insectivore: peer and expert influence affect consumer evaluations of insects as food. Appetite 141: 104338.

Brunner, T.A. and Nuttavuthisit, K., 2019. A consumer-oriented segmentation study on edible insects in Switzerland and Thailand. British Food Journal 122: 482-488.
Castro, M. and Chambers, E., 2019. Consumer avoidance of insectcontaining foods: primary emotions, perceptions and sensory characteristics driving consumers considerations. Foods 8: 351.

Chan, E.Y., 2019. Mindfulness and willingness to try insects as food: the role of disgust. Food Quality and Preference 71: 375-383.

Circus, V.E. and Robinson, R., 2019. Exploring perceptions of sustainable proteins and meat attachment. British Food Journal 121: 533-545.

De Carvalho, N.M., Madureira, A.R. and Estevez Pintado, M., 2019. The potential of insects as food sources - a review. Critical Reviews in Food Science and Nutrition 60: 3642-3652. https://doi.org/10.1 080/10408398.2019.1703170

Elorinne, A-L., Niva, M., Vartiainen, O. and Väisänen, P., 2019. Insect consumption attitudes among vegans, non-vegan vegetarians, and omnivores. Nutrients 11: 292.

Grasso, A.C., Hung, Y., Olthof, M.R., Verbeke, W. and Brouwer, I.A., 2019. Older consumers' readiness to accept alternative, more sustainable protein sources in the European Union. Nutrients 11: 1904.

Hartmann C. and Bearth, A., 2019. Bugs on the menu: drivers and barriers of consumer acceptance of insects as food. In: Sogari, G., Mora, C. and Menozzi, D. (eds) Edible insects in the food sector: methods, current applications and perspectives. Springer Nature, Cham, Switzerland, pp. 45-55.

Hartmann C. and Siegrist, M., 2017a. Insects as food: perception and acceptance. Findings from current research. Ernahrungs Umschau 64: 44-50.

Hartmann C. and Siegrist, M., 2017b. Consumer perception and behaviour regarding sustainable protein consumption: a systematic review. Trends in Food Science \& Technology 61: 11-25.

House, J., 2019a. Modes of eating and phased routinisation: insectbased food practices in the Netherlands. Sociology 53: 451-467.

House, J., 2019b. Are insects animals?: the ethical position of insects in Dutch vegetarian diets. In: Linzey, A. and Linzey, C. (eds) Ethical vegetarianism and veganism. Routledge, London, UK, pp. 201-209.

Iannuzzi, E., Sisto, R. and Nigro, C., 2019. The willingness to consume insect-based food: an empirical research on Italian consumers. Agricultural Economics 65: 454-462.

Jensen, N.H. and Lieberoth, A., 2019. We will eat disgusting foods together - evidence of the normative basis of Western entomophagydisgust from an insect tasting? Food Quality and Preference 72: 109-115.

Kauppi, S-M., Nilstad Pettersen, I. and Boks, C., 2019. Consumer acceptance of edible insects and design interventions as adoption strategy. International Journal of Food Design 4: 39-62.

Kornher, L., Schellhorn, M. and Vetter, S., 2019. Disgusting or innovative-consumer willingness to pay for insect based burger patties in Germany. Sustainability 11: 1878.

Kusch, S. and Fiebelkorn, F., 2019. Environmental impact judgments of meat, vegetarian, and insect burgers: unifying the negative footprint illusion and quantity insensitivity. Food Quality and Preference 78: 103731.

La Barbera, F., Verneau, F. and Coppola, A., 2019. Entomophagy: a contribution to the understanding of consumer intention. Calitatea 20: 329-334. 
Lammers, P., Ullmann, L.M. and Fiebelkorn, F., 2019. Acceptance of insects as food in Germany: is it about sensation seeking, sustainability consciousness, or food disgust. Food Quality and Preference 77: 78-88.

Legendre, T.S., Jo, Y.H., Han, Y.S., Kim, Y.W., Rye, J.P., Jang, S.J. and Kim, J., 2019. The impact of consumer familiarity on edible insect food product purchase and expected liking: the role of media trust and purchase activism. Entomological Research 49: 158-164.

Lombardi, A., Vecchio, R., Borrello, M., Caracciolo, F. and Cembalo, L., 2019. Willingness to pay for insect-based food: the role of information and carrier. Food Quality and Preference 72: 177-187.

Madau, F.A., Arru, B., Furesi, R. and Pulina, P. 2020. Insect farming for feed and food production from a circular business model perspective. Sustainability 12: 5418 .

Mancini, S., Moruzzo, R., Riccioli, F. and Paci, G., 2019a. European consumers' readiness to adopt insects as food: a review. Food Research International 122: 661-678.

Mancini, S., Sogari, G., Menozzi, D., Nuvoloni, R., Torracca, B., Moruzzo, R. and Paci, G., 2019b. Factors predicting the intention of eating an insect-based product. Foods 8: 270.

Onwezen, M.C., Van den Puttelaar, J., Verain, M.C.D. and Veldkamp, T., 2019. Consumer acceptance of insects as food and feed: the relevance of affective factors. Food Quality and Preference 77: 51-63.

Orsi, L., Voege, L.L. and Stranieri, S., 2019. Eating edible insects as sustainable food?: exploring the determinants of consumer acceptance in Germany. Food Research International 125: 1085873.

Palmieri, N., Perito, M.A., Macrì, M.C. and Claudio Lupi, C., 2019. Exploring consumers' willingness to eat insects in Italy. British Food Journal 121: 2937-2950.

Parodi, A., Leip, A., De Boer, I.J.M., Slegers, P.M., Ziegler, F., Temme, E.H.M., Herrero, M., Tuomisto, H., Valin, H., Van Middelaar, C.E., Van Loon, J.J.A. and Van Zanten, H.H.E., 2018. The potential of future foods for sustainable and healthy diets. Nature Sustainability 1: 782-789.

Piazza, J., Ruby, M.B., Loughnan, S., Luong, M., Kulik, J., Watkins, H.M. and Seigerman, M., 2015. Rationalizing meat consumption: the 4Ns. Appetite 91: 114-128.

Poortvliet, P.M., Van der Pas, L., Mulder, B.C. and Fogliano, V., 2019. Healthy, but disgusting: an investigation into consumers' willingness to try insect meat. Journal of Economic Entomology 112: 1005-1010.

Powell, P.A., Jones, C.R. and Consedine, N.S., 2019. It's not queasy being green: the role of disgust in willingness-to-pay for more sustainable product alternatives. Food Quality and Preference 78: 103737.

Ruby, M.B. and Rozin, P., 2019. Disgust, sushi consumption, and other predictors of acceptance of insects as food by Americans and Indians. Food Quality and Preference 74: 155-162.

Rumpold, B.A. and Langen, N., 2019. Potential of enhancing consumer acceptance of edible insects via information. Journal of Insects as Food and Feed 5: 45-53. https://doi.org/10.3920/JIFF2018.0041
Sanchez-Sabate, R. and Sabaté, J., 2019. Consumer attitudes towards environmental concerns on meat consumption: a systematic review. International Journal of Environmental Research and Public Health 16: 1220 .

Schäufele, I., Barrera Albores, E. and Hamm, U., 2019. The role of species for the acceptance of edible insects: evidence from a consumer survey. British Food Journal 121: 2190-2204.

Sogari, G., Bogueva, D. and Marinova, D., 2019b. Australian consumers' response to insects as food. Agriculture 9: 108.

Sogari, G., Lui, A. and Li, J., 2019d. Understanding edible insects as food in Western and Eastern societies. In: Bogueva, D., Marinova, D., Raphaely, T. and Schmidinger, K. (eds) Environment, health, and business opportunities in the new meat alternatives market. IGI Global, Hershey, PA, USA, pp. 166-181.

Sogari, G., Menozzi, D. and Mora, C., 2019a. The food neophobia scale and young adults' intention to eat insect products. International Journal of Consumer Studies 43: 68-76.

Sogari, G., Menozzi, D., Hartmann, C. and Mora, C., 2019c. How to measure consumers acceptance towards edible insects? - a scoping review about methodological approaches. In: Sogari, G., Mora, C. and Menozzi, D. (eds) Edible insects in the food sector: methods, current applications and perspectives. Springer Nature, Cham, Switzerland, pp. 27-44.

Steel, C., 2020. Sitopia: how food can save the world. Chatto \& Windus, London, UK.

Stull, V. and Patz, J., 2020. Research and policy priorities for edible insects. Sustainability Science 15: 633-645.

Van den Burg, S.W.K., Dagevos, H. and Helmes, R.J.K., 2019. Towards sustainable European seaweed value chains: a triple P perspective. ICES Journal of Marine Science fsz183. https://doi.org/10.1093/ icesjms/fsz183

Van der Weele, C., Feindt, P., Van der Goot, A.J., Van Mierlo, B. and Van Boekel, M., 2019. Meat alternatives: an integrative comparison. Trends in Food Science \& Technology 88: 505-512.

Van Huis, A., 2020. Nutrition and health of edible insects. Current Opinion in Clinical Nutrition \& Metabolic Care 23: 228-231.

Van Huis, A. Van Itterbeeck, J., Klunder, H., Mertens, E., Halloran, A., Muir, G. and Vantomme, P., 2013. Edible insects: future prospects for food and food security. FAO Forestry Paper no. 171. Food and Agriculture Organization of the United Nations (FAO), Rome, Italy. Available at: http://www.fao.org/docrep/018/i3253e/i3253e.pdf.

Van Thielen, L., Vermuyten, S., Storms, B., Rumpold, B. and Van Campenhout, L., 2019. Consumer acceptance of foods containing edible insects in Belgium two years after their introduction to the market. Journal of Insects as Food and Feed 5: 35-44. https://doi. org/10.3920/JIFF2017.0075

Woolf, E., Zhu, Y., Emory, K., Zhao, J. and Li, C., 2019. Willingness to consume insect-containing foods: a survey in the United States. LWT - Food Science and Technology 102: 100-105. 
